\title{
Prueba inmunocromatográfica rápida en el diagnóstico del moquillo canino
}

\author{
Pablo N.H. Silva ${ }^{1} \otimes \mathbb{0}$; Bianca F. Dallo ${ }^{1 *} \otimes \mathbb{0}$; Anne C.A. Pesenti ${ }^{\otimes} \otimes$;

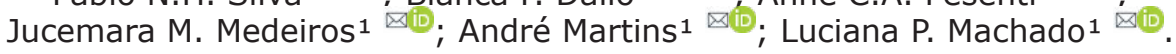

${ }^{1}$ Universidade Federal Da Fronteira Sul (UFFS), Departamento de Medicina Veterinaria, Realeza, Paraná (PR), Brasil.

* Correspondencia: biancadallo@hotmail.com

Recibido: Agosto 2020; Aceptado: Febrero 2021; Publicado: Noviembre 2021.

\section{RESUMEN}

Objetivo. Evaluar el uso de una prueba inmunocromatográfica rápida, asociada con el recuento sanguíneo completo y la búsqueda de inclusiones virales como método de diagnóstico de moquillo en perros. Materiales y métodos. Diecinueve perros, machos y hembras, de 2 a 120 meses, con sospecha clínica de moquillo fueron examinados en el Hospital Veterinario de la UFFS. Se recogieron hisopos conjuntivales para realizar la prueba inmunocromatográfica rápida y también se sacaron muestras de 3 a $5 \mathrm{ml}$ de sangre para el recuento sanguíneo completo y la investigación del corpúsculo de Lentz. Después de realizar el recuento sanguíneo, la sangre se centrifugó y el plasma se usó para realizar una segunda prueba. Resultados. De los 19 animales sospechosos, 7 fueron positivos en la prueba rápida, tanto en plasma sanguíneo como en material de torunda conjuntival, en 2 de estos se observaron cuerpos de Lentz. Conclusiones. La asociación de la prueba inmunocromatográfica rápida con el recuento sanguíneo completo en perros con sospecha clínica de moquillo mejora las posibilidades de diagnóstico de la enfermedad en la fase aguda y la prueba también se puede realizar con plasma sanguíneo, utilizando la misma muestra enviada para el recuento sanguíneo completo. El estudio hematológico reveló que la anemia y la linfopenia son los principales cambios en los animales positivos.

Palabras clave: Inmunocromatografía; linfopenia; Morbillivirus; recuento de células sanguíneas (Fuente: MeSH, DeCS).

\section{ABSTRACT}

Objective. To evaluate the use of a rapid immunochromatographic test, associated with a complete blood count and the search for viral inclusions as a method of diagnosing distemper in dogs. Materials and methods. Nineteen dogs, males and females, aged 2 to 120 months, with clinical suspicion of distemper, were examined at the UFFS Veterinary Hospital. Conjunctival swabs were collected to perform the rapid immunochromatographic test and 3-5 ml blood samples were drawn for complete blood count and Lentz corpuscle investigation. After performing the blood count, the blood was centrifuged, and the plasma was used to perform a second test. Results. Among the 19 suspect 
animals, 7 were positive in the rapid test, both in blood plasma and conjunctival swab material, in 2 of these Lentz bodies were observed. Conclusions. The association of the rapid immunochromatographic test with the complete blood count in dogs with clinical suspicion of distemper improves the chances of diagnosing the disease in the acute phase and the test can also be performed with blood plasma, using the same sample sent for complete blood count. The hematological study revealed that anemia and lymphopenia are the main changes in positive animals.

Keywords: Blood cell count; immunochromatography; lymphopenia; Morbillivirus (Source: MeSH, $\mathrm{DeCS})$.

\section{INTRODUCCIÓN}

El moquillo canino es una enfermedad viral, cosmopolita, que puede resultar en la muerte para los perros y otros carnívoros terrestres. La encefalitis causada por el virus del moquillo canino, un virus de ARN del género Morbillivirus, es la principal causa de muerte. Es una enfermedad altamente contagiosa, con la segunda tasa de mortalidad más alta entre los perros, por lo que tiene una gran importancia epidemiológica (1).

El virus tiene tropismo por tejido linfoide, nervioso y epitelial, y los animales afectados pueden tener síntomas diferentes $(2,3)$. Específicamente en los cánidos domésticos, la edad del animal, así como su estado inmunológico y virulencia de la cepa, definirán la gravedad y la duración del curso de la enfermedad (4).

El primer contacto que provocará una infección generalmente es inhalando el virus. En el tracto respiratorio del huésped, el virus se replicará en el tejido linfoide, quedando posteriormente englobado por los macrófagos, con la consiguiente diseminación a otros órganos. Después del período de incubación, que varía de 7 a 28 días, los animales desarrollan una fiebre bifásica característica, compatible con viremia e infección generalizada de los tejidos linfoides, con depleción linfoide y linfopenia. La inmunosupresión profunda es una consecuencia de la apoptosis y la disfunción espinal. La segunda viremia está asociada con fiebre alta e infección de tejidos parenquimatosos como el tracto digestivo, la piel y el sistema nervioso central (SNC) $(4,5)$.

Las manifestaciones clínicas están directamente relacionadas con la predilección tisular del virus, caracterizándose por descargas nasales, rinitis, conjuntivitis, anorexia, diarrea, dermatitis secundaria, hiperqueratosis de los cojines y el hocico, y con mayor incidencia, los signos neurológicos más variados, dependiendo del grado de implicación y distribución viral del SNC. La hiperestesia, los signos cerebelosos y vestibulares, la falta de coordinación motora, la tetraparesia, el mioclono y la ataxia son signos comunes (6).

Incontables métodos de diagnóstico de moquillo canino existen, en el pasado se intentó el aislamiento viral en cultivos celulares, sin embargo, el estudio demostró ser lento y propenso a resultados falsos negativos cuando el animal no estaba en la fase aguda de la enfermedad (7). Una vez en el sistema nervioso central, en el caso de infecciones persistentes, el virus genera una respuesta local de anticuerpos, y su detección se puede realizar a través del líquido cefalorraquídeo, demostrando ser un método eficaz de diagnóstico virológico en casos de encefalitis (8). También existen métodos indirectos, que detectan y cuantifican anticuerpos virales específicos, con sus ventajas y desventajas (9). La técnica de reacción en cadena de la polimerasa precedida por la transcripción inversa (RT-PCR) se ha utilizado con éxito en animales con signos clínicos de la enfermedad durante algún tiempo (10), aunque no esté disponible en todos los locales de servicios veterinarios y la necesidad de enviar a laboratorios especializados crea un retraso en el diagnóstico.

El diagnóstico más puntual y específico se puede hacer del frotis de sangre, donde se pueden ver los cuerpos de inclusión de Lentz en los glóbulos rojos y los leucocitos. Otros tipos de células también pueden contener el corpúsculo, como las células asociadas con exudados (secreciones oculares) y células epiteliales. Es destacable mencionar que esta visualización no siempre es posible, ya que la presencia viral está estrechamente relacionada con el período de viremia. Incluso en ausencia de cuerpos de inclusión, la infección con el virus del moquillo nunca debe descartarse (11). Sousa et al (12) señaló que $21 \%$ de los animales infectados tendrán cuerpos de inclusión. 
Las pruebas cromatográficas de inmunoensayo proponen un diagnóstico rápido y preciso. La prueba detecta la proteína $F$, una proteína que forma el virus, común en todas las cepas existentes. Se puede realizar con muestras de mucosa conjuntival, suero, plasma, sangre completa o heces de un perro infectado (9). La evaluación utilizando el método inmunocromatográfico debe, cuando sea posible, estar asociada con otros hallazgos (13). De acuerdo com Sousa et al (12), la morfología leucocitaria y los corpúsculos de inclusión siempre deben evaluarse en animales con sospecha de moquillo.

Hay estudios que prueban que las pruebas inmunocromatográficas dependen estrechamente de la muestra biológica utilizada y del grado de infección de la enfermedad, ya que se encontró una alta sensibilidad en $100 \%$ de las muestras de torunda conjuntival (14). Por lo tanto, el objetivo del estudio fue evaluar el uso de una prueba inmunocromatográfica rápida asociada con el recuento sanguíneo completo y buscar inclusiones virales como método de diagnóstico rápido de moquillo en perros con sospecha clínica de la enfermedad. Fue comparado también el uso de la prueba de torunda conjuntival con el uso de plasma sanguíneo de acuerdo con las instrucciones del fabricante.

\section{MATERIAL Y MÉTODOS}

Animales y local. El estudio se llevó a cabo en la Superintendencia de la Unidad del Hospital Veterinario Universitario (SUHVU) de la Universidad Federal de la Frontera Sur, Campus Realeza-PR. Diecinueve perros fueron evaluados, cuya principal sospecha clínica fue moquillo canino, independientemente de su sexo, raza o edad, de julio de 2016 a julio de 2017.

Procedimientos de muestreo. Las muestras foran recojidas después de la antisepsia local con una gasa empapada en alcohol al $70 \%$, se recogieron de 3 a $5 \mathrm{ml}$ de sangre de la vena yugular, usando una jeringa de $5 \mathrm{ml}$ y una aguja de $25 \times 7.5 \mathrm{~mm}$. La sangre se colocó en un tubo que contenía ácido etilendiamina tetraacético (EDTA) como anticoagulante para el rendimiento del recuento sanguíneo completo y el plasma. Con un hisopo estéril se recogió material biológico de la conjuntiva ocular para realizar la prueba inmunocromatográfica en el consultorio.
Prueba inmunocromatográfica rápida. Después de la evaluación clínica del animal, la prueba inmunocromatográfica se realizó con un kit comercial (SensPERT Cinomose-Vencofarma Ltda, Londrina, Brasil) (Figura 1), utilizando el material recogido del hisopo conjuntival, siguiendo las pautas del fabricante. El kit consta de un hisopo estéril, un tubo que contiene una solución tampón, una pipeta y el casete de prueba, que contiene anticuerpos específicos para detectar la proteína $\mathrm{F}$ del virus del moquillo canino. La muestra se depositó en la solución tampón y se depositaron $100 \mu \mathrm{L}$ de la solución en el casete de prueba. La solución tampón se movió por capilaridad, a pesar de que no había antígenos en la muestra, se marcó una primera línea de control (C), lo que garantiza la viabilidad de la prueba. Si hay antígenos, se unen a los anticuerpos presentes en la membrana de nitrocelulosa, marcando como positivo en la línea de prueba $(P)$. El animal se consideró positivo cuando la marca en la línea de prueba ocurrió dentro de los cinco a diez minutos después de aplicar la muestra al casete de prueba, según lo recomendado por el fabricante.

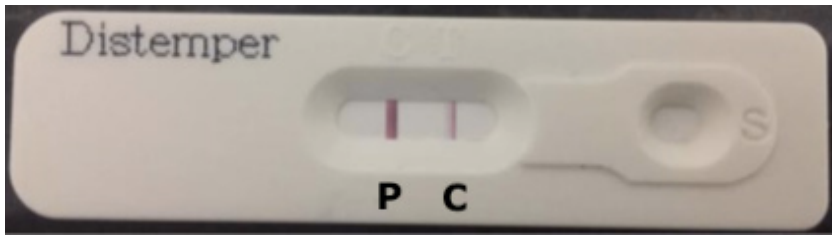

Figura 1. Prueba inmunocromatográfica con resultado positivo. Línea de control (C) y línea de prueba $(P)$.

Pruebas de laboratorio. El recuento sanguíneo se realizó en un contador celular automático (Bio - 2900 Vet - Bioeasy Diagnostical), registrando el recuento total de leucocitos, el número de glóbulos rojos, la concentración de hemoglobina, el volumen corpuscular medio (CMV), la concentración de hemoglobina corpuscular media (CHCM) y el coeficiente de variación de la distribución de los diámetros de los eritrocitos (RDW-CV - Red Cell Distribution Distribution Width). El hematocrito se determinó por el método de microhematocrito (centrifuga de hematocrito NI1807, Nova Instrumente, Piracicaba-SP, Brasil). En el frotis de sangre teñido con un colorante hematológico rápido del tipo Romanowsky (Panótico Rápido LBLaborclin Ltda, Pinhais, Brasil), se realizó el examen diferencial de leucocitos en 100 células, 
la evaluación morfológica y la investigación del cuerpo intra-eritrocitario / intraleucocítico de Lentz. Después de realizar el recuento sanguíneo, la sangre se centrifugó para obtener el plasma y se diluyeron $200 \mu \mathrm{l}$ en $200 \mu \mathrm{l}$ de solución tampón. Después de la homogeneización, se transfirieron $100 \mu$ de la dilución al casete de prueba, que se utilizó para la investigación cualitativa de partículas virales mediante la misma prueba inmunocromatográfica rápida.

Análisis estadístico. A partir de los resultados de la prueba rápida y la observación de los corpúsculos de inclusión, los animales se reorganizaron en dos grupos: grupo positivo (GP), con animales con un resultado positivo en la prueba rápida y grupo sospechoso (GS), en el que los animales siguen siendo sospechosos, esto es fueron negativos en la prueba rápida y no tenían corpúsculos de Lentz. Se aplicó la prueba de Mann-Whitney para evaluar la diferencia entre los datos hematológicos GP y GS, con un nivel de significación del $5 \%$.

Consideraciones éticas. Los dueños estuvieran de acuerdo con la toma de muestra, puesto que el procedimiento no causaría ningún daño o alteración al perro. La experimentación cuenta con la aprobación de la Ética y Experimentación animal (23205.003857 / 2016-56).

\section{RESULTADOS}

Los resultados de las pruebas inmunocromatográficas fueron los mismos en los dos materiales biológicos probados, la secreción ocular y el plasma sanguíneo, siete animales (33.3\%) mostraron resultados positivos en ambas muestras (GP). El resto de los animales evaluados permanecieron sospechosos (GS). En el GP, la edad varió de 4 meses a 6 años, $57.14 \%$ eran hembras $y$, en relación con la raza, predominaban los animales de raza pura $(85.7 \%)$.

Los resultados de la evaluación hematológica se muestran en la tabla 1 . El análisis estadístico de los cambios hematológicos mostró una diferencia significativa entre los grupos. En el eritrograma, el GP presentó valores más bajos para el hematocrito y en el leucograma valores más bajos para los linfocitos y monocitos. No hubo diferencias significativas entre los grupos para el recuento de plaquetas y las concentraciones de proteínas plasmáticas. Se observó trombocitopenia en el $28.5 \%$ de los animales en el GP, mientras que ningún animal en el GS presentó trombocitopenia.

Tabla 1. Resultados de la evaluación hematológica y concentración de las proteínas séricas totales (PST) de 19 perros del municipio de Realeza / Paraná con sospecha clínica de moquillo, agrupados a partir del resultado de la prueba inmunocromatográfica en positivos, los reactivos y sospechosos y los animales no reactivos.

\begin{tabular}{|c|c|c|c|c|}
\hline \multirow{2}{*}{ Parámetros } & \multicolumn{4}{|c|}{ Mediana (Percentil 25; Percentil 75) } \\
\hline & VR & Positivos $(n=7)$ & Sospechosos $(n=12)$ & p valor \\
\hline Eritrocitos (x $\left.10^{6} \mu \mathrm{L}\right)$ & $5.5-8.5$ & $5.0(4.05 ; 5.3)$ & $5.4(4.33 ; 6.6)$ & 0.259 \\
\hline Hemoglobina (g/dL) & $12-18$ & $9.4(8.4 ; 12.4)$ & $13.1(10.3 ; 16.2)$ & 0.091 \\
\hline Hematocrito (\%) & $37-55$ & $30(26.2 ; 38)^{b}$ & $44(33 ; 48)^{a}$ & 0.035 \\
\hline $\operatorname{VCM}(f L)$ & $60-77$ & $65.4(63.8 ; 73.9)$ & $66.5(62.6 ; 70.8)$ & 0.710 \\
\hline CHCM (\%) & $32-36$ & $31.8(29.3 ; 33.3)$ & $32.3(28.2 ; 33.3)$ & 0.767 \\
\hline RDW-CV (\%) & $11-15^{\varphi}$ & $14.9(14.3 ; 15.8)$ & $14.4(13.9 ; 15.3)$ & 0.762 \\
\hline PST (g/dL) & $6-8$ & $6.4(6.2 ; 6.85)$ & $5.8(4.6 ; 7.1)$ & 0.297 \\
\hline Plaquetas (x 103éls $\mu \mathrm{L}$ ) & $200-500$ & $324(140 ; 376)$ & $320(269 ; 458)$ & 0.536 \\
\hline Leucocitos totales ( $\times 10^{3}$ céls $\mu \mathrm{L}$ ) & $6-17$ & $10.1(8.9 ; 12.6)$ & $17.5(11.3 ; 21.1)$ & 0.099 \\
\hline Neutrófilos (x 103céls $\mu \mathrm{L}$ ) & $3-11.5$ & $8.3(5.5 ; 11.7)$ & $12.1(6.4 ; 15.7)$ & 0.277 \\
\hline Linfocitos (x $10^{3}$ céls $\mu \mathrm{L}$ ) & $1-4.8$ & $0.55(0.38 ; 2)^{\mathrm{b}}$ & $2.6(1.8 ; 2.9)^{a}$ & 0.019 \\
\hline Eosinófilos (x $10^{3}$ céls $\mu \mathrm{L}$ ) & $0.1-1.25$ & $0.1(0.02 ; 0.2)$ & $0.52(0.11 ; 1.28)$ & 0.070 \\
\hline Monocitos (x $10^{3}$ céls $\mu \mathrm{L}$ ) & $0.15-1.35$ & $0.4(0.32 ; 0.69)^{\mathrm{b}}$ & $1.8(1 ; 3.1)^{a}$ & 0.005 \\
\hline Basófilos (x 10³céls $\mu \mathrm{L}$ ) & $0-300$ & 0.0 & $60.4 *$ & - \\
\hline
\end{tabular}

$\mathrm{VR}=$ Valores de referencia (15).

$\varphi$ Valor de referencia del analizador de hematología;

ab En la misma línea, indican una diferencia significativa por la prueba de Mann-Whitney $(p<0,05)$;

$\mathrm{VCM}=$ volumen corpuscular médio; $\mathrm{CHCM}=$ concentración de hemoglobina corpuscular media;

$\mathrm{RDW}=$ Red Cell Distribution Width; PST= Proteínas séricas totales; $*$ Media. 
En la evaluación morfológica, se observaron linfocitos reactivos en $28.6 \%$ de los animales positivos y en el $50 \%$ de los animales sospechosos. Se observaron corpúsculos de Lentz intraeritrocitos e intra-leucocitos en dos animales del GP, lo que representa el $9.5 \%$ del total de muestras y el $28.6 \%$ de los animales del GP. Ningún perro negativo para la prueba rápida mostró corpúsculo de Lentz.

\section{DISCUSIÓN}

La orientación del fabricante responsable por el kit para la detección del virus del moquillo fue la realización de la prueba con material recolectado con un hisopo de la secreción nasal y ocular en perros. En el presente estudio, se puede ver que el uso de plasma sanguíneo mostró la misma seguridad en el resultado. El uso de plasma permite al clínico que no tiene el kit en el momento de la consulta enviar la muestra a otro veterinario o laboratorio para su desempeño.

En cuanto a la frecuencia de perros detectados como positivos en el presente estudio, los resultados fueron superiores a los estudios previos que evaluaron perros con sospecha clínica de moquillo. Santos et al. (13), detectaron antígenos de moquillo canino por ensayo inmunocromatográfico en el $19.9 \%$ de los perros con sospecha clínica, utilizando hisopos de mucosa conjuntival como material biológico.

En el estudio de Curti et al (9), también se realizaron muestras de mucosa conjuntival de perros sospechosos de moquillo, con un $21.2 \%$ de animales positivos para antígenos del moquillo en el kit de inmunoensayo. Vale destacar que en el estudio de Curti et al (9) el diagnóstico de moquillo fue confirmado por RT-PCR, no hubo falso positivo en la prueba rápida, sin embargo, en seis animales con signos sistémicos, neurológicos o ambos, la prueba de inmunoensayo fue negativa pero hubo confirmación de moquillo por RT- PCR. Demostrando que en el moquillo la sensibilidad de las pruebas rápidas es inferior al diagnóstico molecular, y la posibilidad de enfermedad en animales no reactivos no debe excluirse.

An et al (14) realizaron un ensayo inmunocromatográfico en 66 animales con síntomas clínicos sugestivos de moquillo, a partir de muestras de sangre, secreción nasal y un hisopo conjuntival. La mayoría de los perros eran jóvenes, con signos clínicos sistémicos y agudos. Todos los animales fueron positivos para la prueba y en 2 animales el resultado se consideró falso positivo en comparación con la PCR. El estudio reveló una mayor especificidad cuando se analizó a partir de muestras de mucosa conjuntival.

En las pruebas realizadas en el presente estudio, hubo diferencias en el tono de las líneas que marcan el enlace antígeno-anticuerpo que hacen que el resultado sea positivo. Esta tinción puede sugerir la concentración del antígeno en el material biológico estudiado, es decir que un animal que se presenta en una fase de viremia y se prueba con la prueba inmunocromatográfica puede presentar una línea de demarcación más fuerte. Lo contrario también es válido, si el animal tiene el virus incubado o en una fase crónica de moquillo, esta prueba puede mostrar una línea con un tono más claro o incluso un falso negativo (14).

En el presente estudio, se observaron corpúsculos de Lentz en el $28.6 \%$ de los animales en el GS. Según Silva et al (16), estas inclusiones representan el efecto citopático en las células, su visualización en eritrocitos y leucocitos confiere un diagnóstico definitivo. La frecuencia de observación del corpúsculo de Lentz en el GS fue similar al estudio de Sousa et al (12), quienes encontraron el $22.2 \%$ de los animales con el corpúsculo de inclusión. Se puede observar que la inclusión de Lentz, aunque confirmatoria, puede no estar presente en la mayoría de los animales con moquillo, ya que su presencia está restringida a la fase de viremia que ocurre en la fase aguda de la enfermedad (16).

Entre los animales negativos en la prueba rápida, dos mostraron signos clínicos compatibles con una condición crónica de moquillo, el kit de inmunoensayo actúa detectando antígenos y no anticuerpos, por lo que no se puede excluir que estuvieran en la fase crónica de la enfermedad (9). En el resto de los animales en el GS, el diagnóstico no fue concluyente y no se puede descartar patologías que tienen síntomas similares, una variedad de signos son comunes en la inflamación del sistema nervioso central y las enfermedades infecciosas (9).

La edad de los animales GP fue diferente de la encontrada en el estudio de Santos et al (13), en el que los animales tenían una edad promedio de 7 años. En cuanto a la raza, predominaron los animales de raza pura y Santos et al (13), sin embargo, Budaszewski et al (2) y Sousa et 
al (12) observaron una mayor prevalencia en animales de raza mixta. La frecuencia de los sexos fue similar, lo que está en confirmidad con lo estudiado por Freitas-Filho et al (17).

En la evaluación hematológica (Tabla 1), la anemia fue el cambio predominante en el grupo positivo $(85.7 \%)$, con diferencia estadística solo para el hematocrito. No hubo diferencia estadística para VCM, CHCM y RDW, la anemia se clasificó predominantemente como regenerativa. La anemia es un hallazgo frecuente en el moquillo, determinado por la destrucción de los eritrocitos por el virus o por la formación de complejos inmunes en su membrana, que causan hemólisis (18). Se observa que los hallazgos hematológicos de diferentes estudios revelan la alta prevalencia de anemia en animales positivos para moquillo canino (19). Silva et al (16) encontraron $61 \%$ de anemia y Santos et al (13) $48.32 \%$.

Para la proteína sérica total no hubo diferencia entre los grupos, los valores estaban cerca del límite inferior de referencia en ambos. Silva et al (16) encontraron hipoalbuminemia en el $100 \%$ de los animales estudiados y en el 54\% de elevación de alfa2 globulina. Los autores justifican que el nivel bajo de albúmina sérica es frecuente en animales con moquillo, debido a la lesión epitelial intestinal con la consiguiente diarrea, apatía y rechazo de los alimentos, y también por vómitos, lo que resulta en una menor ingesta y absorción de proteínas. La elevación plasmática de las globulinas es común en varias reacciones inflamatorias, en particular el componente alfa 2 aumenta significativamente en infecciones virales y bacterianas, como el moquillo.

En el grupo positivo, el recuento total de leucocitos estaba dentro del rango normal y el cambio principal fue la linfopenia, con una diferencia significativa entre los grupos. La linfopenia está relacionada con la predilección viral por el tejido linfoide, lo que causa su atrofia y la posterior disminución de la producción celular (20). Barbosa et al (21) también confirman la inmunosupresión debida al tropismo del virus por el tejido linfoide, que causa linfopenia transitoria, infecta a los linfocitos maduros y causa apoptosis. Se observaron linfocitos reactivos en el $28.6 \%$ de los animales positivos y en el $50 \%$ de los animales del grupo sospechoso, Souza et al (12) observaron este cambio en el $72.2 \%$ de los animales con sospecha de moquillo.

En animales sospechosos, se observó leucocitosis debido a neutrofilia y monocitosis, con una diferencia significativa entre los grupos solo para monocitos, lo que indica un proceso inflamatorio crónico, que puede deberse a moquillo y otras enfermedades (22). En el moquillo, la neutrofilia ocurre en respuesta a una infección bacteriana secundaria, especialmente en la fase crónica (20). Los recuentos de eosinófilos y basófilos fueron similares entre los grupos.

Se ha observado trombocitopenia en el $28.5 \%$ de los animales GP y no hubo diferencias significativas entre los grupos para el número de plaquetas. La reducción en el número de plaquetas es un cambio importante entre los cambios hematológicos de los perros con moquillo, que puede ocurrir con más frecuencia que en el presente estudio, Silva et al (16) encontraron en el $69 \%$ de los perros, Santos et al (13) en $50.33 \%$ y Sousa et al (12) en $38.8 \%$.

Analizando los cambios que fueron más frecuentes, los hallazgos del presente estudio corroboran con los estudios previos. Tudury et al (23), Almeida et al (20), Barbosa et al (21) describen la anemia, la linfopenia y la leucocitosis como los cambios más comunes. La trombocitopenia es descrita por Almeida et al (20) y Souza et al (12). Souza et al (12) también describen la anemia como la alteración más común, seguida de linfocitos reactivos, monocitosis y linfopenia.

In conclusión, a asociación de la prueba inmunocromatográfica rápida con el recuento sanguíneo completo en perros con sospecha clínica de moquillo mejora las posibilidades de diagnóstico de la enfermedad en la fase aguda. Además, la prueba también se puede realizar con plasma sanguíneo, utilizando la misma muestra enviada para el recuento sanguíneo completo. El estudio hematológico reveló que la anemia y la linfopenia son los principales cambios en los animales positivos.

\section{Conflicto de intereses.}

Los autores del presente estudio declaramos que no existe conflictos de intereses con la publicación del presente manuscrito.

\section{Agradecimientos.}

Los autores desean reconocer a la empresa Laboratórios Vencofarma do Brasil LTDA, por el suministro de kits inmunocromatográficos. 


\section{REFERENCIAS}

1. Mangia SH, Moraes LF, Takahira RK, Mott RG. Efeitos colaterais do uso da ribavirina, prednisona e DMSO em cães naturalmente infectados pelo vírus da cinomose. Pesq Vet Bras. 2014; 34(5):449-454. https://doi. org/10.1590/S0100-736X2014000500011

2. Budaszewski RF, Pinto LD, Weber MN, Caldas $E T$, Alves CD, Martella V, et al. Genotyping of canine distemper virus strains circulating in Brazil from 2008 to 2012. Virus Res. 2014; $180: 76-83$. https://doi.org/10.1016/j. virusres.2013.12.024

3. Brito LBS, Pereira OT, Oliveira PAC, Teófilo TS, Oliveira RM, Silva ALA, et al. Aspectos epidemiológicos da cinomose em cães atendidos em um Hospital Veterinário no período de 2011 a 2013. Pubvet. 2016; 10(7):518-522. http:// www.pubvet.com.br/artigo/2895/p-styletextalign-justify-aligncenterstrongaspectosepidemioloacutegicos-da-cinomose-emcatildees-atendidos-em-um-hospitalveterinaacuterio-no-periacuteodo-de-2011a-2013strongp

4. Beineke A, Baumga"rtner, W, Wohlsein P. Cross-species transmission of canine distemper virus - an update. One Health. 2015; 1:49-59. https://doi.org/10.1016/j. onehlt.2015.09.002

5. Temilade BE, Solomon OO, Omotayo OE, Omezuruike OI. Seropositivity of canine distemper virus (CVD) in dogs presenting at Abeokuta, Nigeria. Public Health Res. 2015; 5(4):109-119. http://article.sapub. org/10.5923.j.phr.20150504.05.html

6. Noyce RS, Delpeut S, Richardson CD. Dog nectin-4 is an epitelial cell receptor for canine distemper virus that facilitates virus entry and syncytia formation. J Virol. 2013; 436(1):210-220. https://doi.org/10.1016/j. virol.2012.11.011

7. Shin Y, Mori T, Okita M, Gemma T, Kai C, Mikami T. Detection of canine distemper virus nucleocapsid protein gene in canine peripheral blood mononuclear cells by RTPCR. J Vet Med Sci. 1995; 57:439-445. https://doi.org/10.1292.jvms.57.439
8. Soma T, Uemura T, Nakamoto Y, Ozawa T, Bandai T, Oji T, et al. Canine distemper virus antibody test alone increases misdiagnosis of distemper encephalitis. Vet Rec. 2013; 173(19):477. http://dx.doi.org/10.1136/ $\underline{\text { vr. } 101866}$

9. Curti CM, Arias MVB, Zanutto MS. Avaliacão de um kit de imunoensaio cromatográfico para deteccão do antígeno do vírus da cinomose em cães com sinais sistêmicos ou neurológicos da doenca. Semin Ciênc Agrár. 2012; 33(6):2383-2389. http://dx.doi. org/10.5433/1679-0359.2012v33n6p2383

10. Macedo CI, Peixoto ZM, Castilho JG, Oliveira RN, Rodrigues AC, Achkar SM. Diagnóstico de cinomose canina por RT-PCR em amostras de cães do estado de São Paulo enviadas para diagnóstico laboratorial da raiva. Rev Educ Cont Med Vet Zootec. 2016; 14(1):1821. https://doi.org/10.36440/recmvz. v14i1.31032

11. Leal PDS, Pontes PR, Flausino W, Lopes CWG. Diagnóstico de infeccões concomitantes por cystoisospora ohioensis e o vírus da cinomose-relato de dois casos. Rev Bras Med Vet. 2011 ; 33(3); 184-188. http://rbmv. org/index.php/BJVM/article/view/800

12. Sousa RA, Baião JC, Santos JP, Rocha LB, Machado LP. Achados hematológicos em cães com cinomose em Bom Jesus/ PI. Encicl Biosf. 2015; 11(22):1-10. http://dx.doi.org/10.18677/Enciclopedia Biosfera 2015065

13. Santos JP, Borges CEF, Locce CC, FerreiraJunior A, Bittar ER, Alves DR, et al. Estudo retrospectivo de cães positivos para cinomose, em ensaio imunocromatográfico, atendidos no Hospital Veterinário de Uberaba-MG. Vet Not. $2012 ; 18(2): 31-36$. http://www.seer. ufu.br/index.php/vetnot/article/view/22870

14. An DJ, Kim TY, Song DS, Kang BK, Park BK. An immunochromatography assay for rapid antemortem diagnosis of dogs suspected to have canine distemper. J Virol Methods. 2008; 147:244-249. https://doi. org/10.1016/j.jviromet.2007.09.006 
15. Rizzi TE, Meinkoth JH, Clinkenbeard KD. Normal hematology of the dog. In: Weiss DJ, Wardrop KJ editor. Schalm's veterinary hematology. 6th ed. Iowa: Wiley Blackwell; 2010.

16. Silva ING, Guedes MIF, Rocha MFG, Medeiros CMO, Oliveira LC, Moreira OC, et al. Perfil hematológico e avaliacão eletroforética das proteínas séricas de cães com cinomose. Arq Bras Med Vet Zootec. 2005; 57(1):136139. https://doi.org/10.1590/S0102$\underline{09352005000100019}$

17. Freitas-Filho EG, Ferreira MRA, Dias $M$, Moreira CN. Prevalência, fatores de risco e associacões laboratoriais para cinomose canina em Jataíi-GO. Encicl Biosf. 2014; 10(18):2356-2365. http://conhecer.org.br/ enciclop/2014a/AGRARIAS/prevalencia.pdf

18. Headley AS, Amude AM, Alfieri AF, Alfieri AA, Bracarense APFRL. Epidemiological features and the neuropathological manifestations of canine distemper virus-induced infections in Brazil: a review. Semina: Ciênc Agrár. 2012;33(5):1945-1978. http://dx.doi. org/10.5433/1679-0359.2012v33n5p1945

19. Fung HL, Calzada J, Saldaña A, Santamaria AM, Pineda V, Gonzalez K, et al. Domestic dog health worsens with socio-economic deprivation of their home communities. Acta Trop. 2014; 135:67-74. https://doi. org/10.1016/j.actatropica.2014.03.010
20. Almeida RK, Vasconcelos AC, Carneiro RA, Paes PRO, Moro L. Alterações citológicas do sangue periférico e da medula óssea de cães com cinomose. Arq Bras Med Vet Zootec. 2009; 61(6):1255-1260. https://doi. org/10.1590/S0102-09352009000600001

21. Barbosa TS, Vieira RFC, Viol MA, Soeiro CS, Bomfim SRM, Ciarlini PC. Avaliacão laboratorial da cinomose canina - estudo retrospectivo de 25 casos no município de Aracatuba, SP. Rev Cienc Agrovet. 2011;10(2):113-118. http://www.revistas. udesc.br/index.php/agroveterinaria/article/ view/5274

22. Weiser G. Interpretacão da resposta leucocitária na doenca. In: Thrall MA, Weiser G, Allison RW, Campbell TW. Hematologia e bioquímica clínica veterinária. São Paulo: Roca; 2015.

23. Tudury EA, Arias MVB, Bacarense AFL, Megid J, Junior RFD. Observac̃es clínicas e laboratoriais em cães com cinomose nervosa. Cienc. Rural. 1997;27(2):229335. https://doi.org/10.1590/S0103$\underline{84781997000200010}$ 